\title{
On the phonetic status of syllabic consonants: Evidence from Slovak
}

\author{
MARIANNE POUPLIER ${ }^{\star}$ and ŠTEFAN BEŇUŠ** \\ *Ludwig-Maximilians University Munich \\ ${ }^{\star *}$ Constantine the Philosopher University in Nitra, \\ Institute of Informatics, Slovak Academy of Sciences
}

\section{Abstract}

This paper investigates the phonetic correlates of syllable structure, focusing on syllabic consonants. Cross-linguistically, syllables containing consonantal nuclei are often subject to a number of restrictions compared to their vocalic counterparts. However, some languages, like Slovak, allow relatively freely distributed syllabic liquids. Phonetic studies of syllable structure have shown that the vowel provides the basis for the articulatory coordination relationships within a syllable, and consonant-vowel timing patterns have been identified as a primary phonetic correlate of syllable structure. However, how coordination relationships within a syllable are organized when a consonant occupies the nucleus is largely unknown. We investigate whether in Slovak, syllabic consonants change their consonantal kinematics to approach a more vowel-like articulation and whether vowel-less syllables differ in their articulatory timing characteristics from canonical syllables containing vowels. Our results show that a consonant does not change to be more like a vowel in its articulatory dynamics when occupying the nucleus position. However, we find consistent effects in articulatory timing in that consonantal syllables show less overlap on a variety of measures compared to vocalic syllables. We argue that the typological possibility for syllabic consonants may be related to the general consonant timing pattern of a language.

\section{Introduction}

\subsection{Consonants and vowels}

True linguistic universals are hard to come by; most of them are near-universals in that they are not without exception, such as the preference of onset over coda (see Butcher 2006 for an overview; Sommer 1970). An apparently uncontested universal is, however, the basic distinction between consonants and vowels: While languages differ substantially in their choice of sound inventories, all spoken languages distinguish consonants from vowels. This distinction is of course tightly interrelated with syllable structure; the consonant-vowel alternation is the basis 
for the syllabic organization of language. ${ }^{1}$ Vowels as nuclei constitute the basic timing unit of the prosodic hierarchy, and thus provide the foundation for speech rhythm in the broadest sense. Phonologically as much as phonetically, consonants are oriented with respect to a vocalic nucleus. This has been modeled in many ways, ranging from phonological syllabification algorithms (Blevins 1995), the sonority sequencing principle (Selkirk 1982) and syllable cut theory (Vennemann 1991, 1992), to a syllable model based on the mandibular cycle (Redford 1999; MacNeilage and Davis 2000) and the coupled oscillator view of syllable structure (Browman and Goldstein 2000; Nam et al. 2009). Phonetically, vowels and consonants differ considerably in their properties and this seems to be related to, if not the very basis of, their behavior within a syllable: The syllable margin is always consonantal, the nucleus preferably vocalic. This strong preference may arise due to vowels providing the basis for articulatory coordination within the syllable. Many studies have shown how consonants are coordinated articulatorily with respect to their vocalic nucleus and how consequently pre- and postvocalic consonants differ systematically from each other (Sproat and Fujimura 1993; Krakow 1999 and many others). In an influential paper many years ago Öhman (1966) proposed that consonants are superimposed on a continuous vowel articulation. Many researchers have further recognized that the syllable has a physiological basis, and all of these proposals crucially build on a vocalic nucleus providing an organizational basis for consonantal articulations (Stetson 1951; Browman and Goldstein 1988; Redford 1999; MacNeilage and Davis 2000); overviews are provided by Tillmann (1964) and more recently by Krakow (1999). In short, vowels seem to serve a very specific function within the syllable and the general confound between a vowel and the nucleus position may be no accident.

Upon consideration of these fundamental facts about sound structure, it is rather curious that we find an exception to the rule: In some instances, consonants can behave phonologically like vowels in that they function as syllable nuclei. Comparatively little work has been done on the typology of syllabic consonants specifically. The most comprehensive typological overview is provided by Bell (1970, 1978), and we will draw mainly on this source in our statements about the crosslinguistic properties of syllabic consonants. In his survey of 182 languages Bell states the following:

Syllabic consonants are not particularly rare. The impression that they are secondary phenomena comes rather from the restricted environments in which they occur, and the related fact that their syllabicity is usually predictable at a relatively low level of the phonology. In our sample, there are only 12 languages in which the syllabicity of consonants is not predictable from the segmental context, and many of these are doubtless predictable, given the constituent structure. (1970: B15)

Syllabic consonants are predictable in most languages in that they typically occur in unstressed position at the edges of constituents and may alternate with a schwa pronunciation, as for instance the postlexical syllabic consonants in English 
or German. Relatively unrestricted syllabic consonants with an unpredictable distribution are rare, with Tashlhiyt Berber being a prominent exception hotly debated in the current literature. It has been argued that in Tashlhiyt, any consonant, even an obstruent can serve as syllabic nucleus (Dell and Elmedlaoui 2002; Ridouane 2003). More common are languages featuring relatively freely distributed nasals or liquids. One group of languages with syllabic nasals are the languages of West Africa such a Yoruba. Relatively freely distributed syllabic liquids can be found in several Slavic languages. One such language is Slovak, which will be at the focus of our investigation.

The most common explanation for the asymmetry between consonants and vowels is built on sonority. The segmental sonority hierarchy discretizes a continuous phonetic phenomenon assumed to be linked to the phonetic features of acoustic energy and/or the degree of vocal tract opening. The ranking of a segment on the sonority scale is closely linked to the phonotactic behavior of a segment within the syllable and the syllable position a segment can occupy (e.g., Selkirk 1982; Clements 1990; McCarthy 2003; Prince and Smolensky 2004). More sonorous sounds are preferred over less sonorous ones for the syllable nucleus while the opposite applies to the syllable onset (the coda represents an intermediate case). The difference between languages like Slovak or Tashlhiyt Berber that have less restricted distribution of consonantal nuclei, and English or German is assumed to be linked to the phonological domain at which the syllabic consonants are active. In the first group of languages they are active in so called lexical phonology, which is characterized by morpho-phonological alternations. Syllabic consonants in the second group of languages are intimately related to word edges, depend on speaking style and tempo, and are thus primarily a part of postlexical phonology. ${ }^{2}$

In our quest for the origins of the restricted nature of syllabic consonants, we pursue two possibilities. Firstly, we ask whether syllable positions may be identified kinematically, and secondly, we investigate whether it is articulatory timing that differentiates consonantal and vocalic nuclei. These two research strategies have been chosen for the following reasons: Conceivably a consonantal nucleus may not provide the same possibilities for articulatory coordination compared to a vocalic nucleus unless the consonant changes its kinematics to approach a more vowel-like articulation. Phonetic studies of syllable structure (reviewed in more detail below) suggest that the vowel is the basis of articulatory coordination in continuous speech. Vowels differ kinematically from consonants in that they always involve a movement of the entire tongue body, are overall relatively unconstricted compared to consonants and are relatively slow in their movement. One piece of evidence in support of our hypothesis is the fact that typologically, syllabic consonants do not usually take complex onsets and codas; they are much more restricted in syllable complexity compared to vocalic syllables (Bell 1970). If they do take complex onsets, as in Slovak, it may therefore be the case that these consonants in nucleus position differ from their onset and coda counterparts by 
being kinematically slower in their movements, longer in duration and showing generally lower stiffness. This reasoning is also related to a treatment of glides, as suggested for instance by Pike (1943) and taken up by Clements (1990), which regards glides as vowels in the syllable edge position. Without wanting to get into the details of the debate surrounding glides here, this view provides an analogous case to the argument we pursue in this paper: If one views glides as "vowels out of place" (Lisker 1995), then these sounds illustrate how a gesture's kinematic parameterization changes as a function of syllable position. Glides, being faster and generally more dynamic compared to vowels then constitute one piece of evidence for the possibility of syllable edges being defined by different articulatory kinematics compared to the syllable nucleus. Syllabic consonants provide us with the opportunity to investigate the complementary case, namely how a consonant in the nucleus position differs from the same consonant in syllable edge position.

The second avenue of investigation we pursue is concerned with articulatory timing. In particular the work of Krakow $(1993,1999)$ has shown that the syllable can, from a phonetic perspective, be primarily understood as a domain of articulatory timing. Onset-vowel and vowel-coda timing differ significantly from each other. In particular, it has been hypothesized that onsets, but not codas, are timed synchronously to the vowel. These syllable position specific timing differences have been related to phonological asymmetries between onsets and codas such as for instance a cross-linguistic preference for onsets, or the moraicity of codas (Browman and Goldstein 1995; Nam 2007a; Nam et al. 2009). Syllabic consonants offer us the opportunity to investigate onset-nucleus timing without the consonant vowel confound the nucleus position is usually subject to. In particular, if we find that onset-nucleus timing differs as a function of the nucleus being a vowel or a consonant, this may be part of an explanation as to why syllabic consonants are typologically rare (more detail on the phonetic correlates of syllable structure and the hypothesis of preferred timing patterns follows below).

Our current study aims to contribute to our understanding of the restricted nature of syllabic consonants by investigating the syllabic consonants of Slovak. We will now review the phonological evidence that establishes the liquids as syllable nuclei in Slovak and present the distributional properties of Slovak vowel-less syllables. In the following, we will refer to syllables with a consonant nucleus as consonantal syllables and to syllables with a vowel nucleus to vocalic syllables. Symbolically, a consonantal nucleus will be denoted as L, a vocalic nucleus with $\mathrm{V}$; thus a CLC syllable contains three consonants with $\mathrm{L}$ being either $/ 1 /$ or $/ \mathrm{r} /$ in the nucleus position. For identifying individual consonants in any consonant sequence, we refer to the consonants numerically ascending from left-to-right as $C_{1} C_{2} V_{1} C_{2}$.

\subsection{Slovak syllabic consonants}

Slovak permits the liquids $/ 1 /$ and $/ r /$ to be the nucleus of a syllable, where $/ r /$ is an apical trill in all syllable positions and $/ 1 /$ is assumed to have a dorsal retrac- 
tion gesture (i.e. is a "dark /1/"). Syllabic consonants obligatorily take an onset and require a following consonant in the form of a coda or the onset of a following syllable in polysyllabic words. This means that the minimal sequence containing a consonantal nucleus is $\mathrm{CL}(\$) \mathrm{C}$ (\$ marks a possible syllable boundary). ${ }^{3}$ As a result, syllabic consonants do not occur in absolute word-initial or -final position. With schwa being absent from the Slovak vowel inventory, syllabic consonants also never alternate between a pronunciation with or without schwa (as is the case for postlexical syllabic consonants in other languages) and their occurrence is independent of speaking rate or style. Moreover, in morphologically simple roots, Slovak syllabic liquids occur almost exclusively in the prosodically prominent leftmost syllable, that is, they are not confined to prosodically weak positions. The rich affixal morphology of Slovak and fixed word-initial stress render the distribution of syllables with consonantal nuclei within words unconstrained.

Consonantal syllables can take complex onsets with up to three onset consonants (e.g., štrk 'gravel', štvrt' 'quarter' or smrt' 'death', with /r/ providing the nucleus in all three cases), but they only allow for a limited set of complex codas (cf. words like sínc 'sun-Gen.Pl.' and sŕnk 'deer-Gen.Pl.' with a homorganic coda cluster). ${ }^{4}$ In this connection it should be pointed out that complex codas in vocalic syllables are also infrequent in Slovak. Phonological rules that target the syllable nucleus apply independently of whether the nucleus is occupied by a vowel or a consonant, thereby confirming that the consonants truly occupy nucleus position. For example, Slovak shows a complex set of phonemic length alternations for syllable nuclei, mainly triggered by affixation or by the rhythmic law (Kenstowicz and Rubach 1987; Rubach 1993). The rhythmic law states that a long nucleus becomes short if the immediately preceding syllable contains a long nucleus. Syllabic consonants participate in these length alternations just as vowels do, and serve as both triggers and targets as illustrated in (1). That is, /1/ and / r/ can, like vowels, be long or short if and only if they are in the nucleus. In onset and coda positions /1/ and $/ \mathrm{r} /$ behave like other consonants and do not exhibit any length alternations since Slovak does not have true geminate consonants. ${ }^{5}$

In the examples throughout the paper we will use Slovak orthography since it matches pronunciation fairly closely. Phonemic length is indicated by an acute accent on both vowels and liquids, $<\mathrm{ch}>$ represents the velar fricative $[\mathrm{x}],<\mathrm{y}>$ and $<\mathrm{i}>$ both represent the same high front vowel, and a haček or apostrophe associated with coronal consonants distinguishes the palatal consonants from the alveolar ones.

(1) Length alternations of consonantal (left) and vocalic (right) nuclei with hyphens indicating morpheme boundaries

- Lengthening in genitive plural

$\begin{array}{llll}\text { srn- } a(\text { deer }) & \text { sín } & \text { ran- } a \text { (wound) } & \text { rán } \\ \text { jablk-o (apple) } & \text { jablk } & \text { bral-o (hill) } & \text { brál }\end{array}$


- Lengthening preceding diminutive suffix $-o k$

$\begin{array}{llll}\text { vrch (hill) } & \text { vŕš-ok } & \text { hrad (castle) } & \text { hrád-ok } \\ \text { chlp (hair) } & \text { chĺp-ok } & \text { sud (barrel) } & \text { súd-ok }\end{array}$

- Shortening through suffixation pred $l^{\prime} z-i-t$ ' (lengthen) predlž-ova- $t^{\prime} \quad z v a ́ z ̌-i-t$ ' (think) zvaž-ova- $t$ ' vykrm-i-t' (feed) vykrm-ova-t' zníz-i-t' (lower) zniž-ova-t'

- Rhythmic law

\begin{tabular}{|c|c|c|c|c|c|}
\hline Word & Gen.Pl. & Dat.P1. & Word & Gen.Pl. & Dat.P1. \\
\hline$s r n-a$ (deer) & srn-ách & srn-ám & $r y b-a$ (fish) & $r y b$-ách & ryb-ám \\
\hline$v \ln -a$ (wave) & vln-ách & vln-ám & ruk-a (hand) & ruk-ách & ruk-ám \\
\hline & & & trá 1 & & \\
\hline dížk- & dĺžk & $m$ & lúk-c & ch & $a m$ \\
\hline
\end{tabular}

In sum, phonotactically, Slovak syllabic consonants are more restricted compared to vowels in that only the liquids may function as nucleus (as opposed to any consonant of the inventory), and they show slightly reduced possibilities for minimal/maximal syllable complexity. Nonetheless, syllabic consonants can appear in both stressed and unstressed position, and can take complex onsets. With respect to phonological rules, Slovak syllabic consonants behave just like their vocalic counterparts; these rules target the nucleus position independently of whether the nucleus is a vowel or a consonant. We will now turn to a brief review of the known phonetic correlates of syllable structure as well as previous phonetic work on syllabic consonants.

\subsection{Phonetic correlates of syllable structure}

In order to assess any potentially present phonetic properties of the nucleus position, we first present a brief summary of known differences between onsets and coda consonants (for an overview see Krakow 1999). While onset consonants usually show a greater spatial excursion compared to coda consonants (Byrd 1996), particularly more recent phonetic approaches have considered the syllable primarily as a domain over which timing relations (and hence coarticulatory patterns) between consonants and vowels and successive consonants are specified (e.g., among many others, Kozhevnikov and Chistovich 1965; Nittrouer et al. 1988; Sproat and Fujimura 1993; Krakow 1993, 1999). For one thing, consonants in onset clusters are less overlapped compared to coda clusters, and also consonantvowel timing differs for onset and coda. Coordination in onset is synchronous while articulatory coordination in coda is asynchronous, although synchronous coordination has also been reported for codas for some languages (see Gick et al. 2006). Some studies for English also show that the relative timing of consonants in codas is generally less well understood (Byrd 1995; Marin and Pouplier 2010). English nasals are a well-known example illustrating the differences in timing between onset and coda. While in onset position the velum gesture for a nasal reaches 
its target simultaneously with the oral gesture, in coda, the velum gesture extends to the preceding vowel and the oral gesture begins its movement only when the velum has already reached its lowest position (Krakow 1993; Byrd et al. 2009). In onset, consonant-vowel production happens (near-)simultaneously. For a production of a labial onset followed by a vowel, for example, the vowel gesture may start before the lip gesture has reached its target (Perkell 1969; Löfqvist and Gracco 1999), but the vowel extends temporally beyond the consonant, presumably due to its lower stiffness parameterization.

A model that seeks to predict the differential timing patterns of onset and coda has been provided by the coupled oscillator model of syllable structure (Browman and Goldstein 2000; Nam 2007b; Nam et al. 2009). This model hypothesizes that in onset, the consonant gestures are coordinated in-phase with the vowel, but antiphase with each other, producing a so-called C-center timing pattern on the surface. That is, independently of how many consonants a given onset is composed of, the onset as a whole maintains a consistent timing relation with the vowel. This has been taken to mean that there is a stable coordination relationship between the onset as a unit and the vowel. Empirically, the global timing of the onset as a unit to the vowel has been pinned down by means of the 'C-center' effect. It could be shown that under changing onset complexity, the temporal midpoint of the onset as a whole (be it a singleton consonant or consonant cluster) exhibits little variability in its timing to the vowel. For example, comparing the temporal distance of $/ \mathrm{k} /$ in the English word $c a b$ to a constant anchor point in the vowel with the distance of $/ \mathrm{k} /$ in the word $s c a b$ to that same anchor point, we find that $/ \mathrm{k} /$ overlaps more with the vowel (is closer to the anchor point) in scab. This is illustrated as 'rightedge' in Figure 1. What remains invariant however, is the temporal distance of the midpoint (C-center) of the onset, be it a singleton or cluster, to the vowel. The hypothesized stability of the $\mathrm{C}$-center for onsets has been confirmed empirically for a variety of different languages such as Italian, Georgian, German, and English and these timing patterns have been used as a diagnostic for syllable structure in

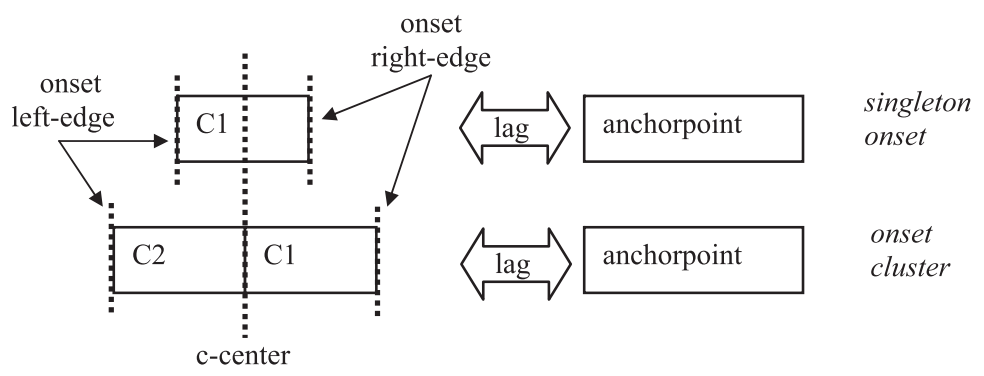

Figure 1. Schematic illustration of the C-center effect. The C-center by hypothesis maintains an invariant timing relationship to the anchorpoint irrespective of onset complexity. In contrast, the temporal lag of the so-called left-edge and right-edge of the onset to the anchorpoint changes with the number of consonants in the onset. 
Tashlhiyt Berber and Moroccan Arabic (Honorof and Browman 1995; Goldstein et al. 2007; Hermes et al. 2008; Shaw et al. 2009; Marin and Pouplier 2010; Pouplier accepted). We will therefore use this effect in our present study to investigate how increasing onset complexity affects the articulatory coordination in syllables with vocalic and consonantal nuclei.

\subsection{The phonetics of syllabic consonants}

Only a few studies have investigated syllables with consonantal nuclei empirically; in these the focus has been on the question of whether there are traces of potentially present underlying vowels which might render the seemingly consonantal syllables underlyingly CV. For Tashlhiyt Berber, the syllabic status of consonants has been debated, since they can be accompanied by schwas. The phonetic quality of the schwa has been reported to vary, which has led Coleman (2001) to posit the presence of an underlying lexical vowel, which would render these consonantal syllables in fact canonical syllables with a vocalic nucleus. Others (Dell and Elmedlaoui 1988, 2002; Ridouane 2003; Fougeron and Ridouane 2008, see also Ridouane and Fougeron 2011 in this issue) have accumulated strong evidence that the schwa is the consequence of an open transition in the sense of Catford (1977). Phonological arguments further establish the syllabic status of these consonants (Dell and Elmedlaoui 2002). A systematic study of the kinematic properties of syllabic consonants themselves is provided by Fougeron and Ridouane (2008). They investigated on the basis of EPG data whether the consonant $/ \mathrm{k} /$ changes in its kinematics or in its timing relationships with the surrounding segments as a function of syllable position, with one of the positions being the nucleus. In their data for a single native speaker of Tashlhiyt Berber, they find that syllabic consonants are generally less variable compared to their onset and coda counterparts and that they are less overlapped by a following (non-coda) consonant, but more overlapped by a preceding (onset) consonant. Syllable position had no effect on closure duration. There was little consistent effect regarding the kinematics of the syllabic consonant, although measures like velocity and stiffness are difficult to estimate on the basis of EPG, especially so for a velar consonant. If anything, the consonant showed faster closure formation and more EPG contact in nucleus position compared to onset/coda position.

Our present research is related to the study of Fougeron and Ridouane in that it investigates the kinematic properties of consonants in the nucleus position. Going beyond their study, we further focus on the question of whether the articulatory coordination within a syllable differs as a function of the vocalic or consonantal nature of the nucleus. We focus on Slovak because phonologically, the nuclear status of syllabic consonants is uncontroversial (see above), and native speakers are readily available, enabling the recording of multiple, phonetically naive subjects. Little is known about the phonetic properties of these consonants. Slovak 
syllabic /r/, according to Král' and Sabol (1989), commonly features two taps. They also mention that nucleus $/ 1 /$ might have slightly greater lingual contact with the hard palate and be 'stronger' compared to onset and coda /1/s. Nucleus (interconsonantal) /r/ tends to be produced with two apical contacts more consistently, while intervocalic $/ \mathrm{r} /$ more commonly has only a single contact. However, rigorous phonetic studies focusing on the production of these consonants are missing.

Empirically, we employ two classes of measures in pursuit of our research question: Conceivably, if a language allows syllabic consonants to take onsets and codas, these syllabic consonants could be more vowel-like in their kinematics compared to their onset and coda equivalents, therefore affording coordination relationships similar to $\mathrm{CV}$. The nucleus position would in this case be characterized by a significant change in the kinematic properties of a consonant in the nucleus position compared to the same consonant in onset/coda position. Secondly, we investigate articulatory coordination in syllables with vocalic and consonantal nuclei by means of different timing measures. We compare consonant cluster as well as onset-nucleus coordination in vocalic and consonantal syllables.

\section{Methods}

We present data from five native speakers of Slovak. All of them were naïve as to the purpose of the experiment. They were all living in Munich at the time of the recording, but reported speaking Slovak on a regular basis and had lived outside of Slovakia for less than two years.

Articulatory data were recorded at a sampling rate of $200 \mathrm{~Hz}$ by means of articulography (EMA, Carstens Medizinelektronik); acoustic data were recorded simultaneously at a sampling rate of $32768 \mathrm{~Hz}$. For the EMA recordings, four reference sensors were used in order to be able to correct for head movement. Further sensors were attached to the upper and lower lips, the lower incisors to record jaw movement, and to the tongue. Four sensors were placed on the tongue with the most anterior sensor being about $1 \mathrm{~cm}$ behind the actual tongue tip (henceforth TT) and the most posterior sensor being in the velar/dorsal region of the tongue (henceforth TD). The two other sensors were equally spaced between the most anterior and posterior sensors (henceforth TB1 for the more anterior, TB2 for the more posterior sensor). Lip aperture (henceforth LA) was calculated as the Euclidean distance between the upper and lower lip sensors. Standard calibration and postprocessing procedures were conducted for each data recording session (Hoole and Zierdt 2010). The data were corrected for head movement and rotated to each subject's occlusal plane. The audio data were downsampled during postprocessing to $16384 \mathrm{~Hz}$. The kinematic signals were lowpass filtered with a $20 \mathrm{~Hz}$ cut-off frequency for all but the reference sensors, which were filtered at $5 \mathrm{~Hz}$, and the tongue tip sensor, which was filtered with a $60 \mathrm{~Hz}$ cut-off frequency. 


\subsection{Stimuli}

Subjects were asked to read the sentences presented to them on a computer screen, one at a time. All target words were embedded in the carrier phrase " $U z z$ hovorime __ hodinu", meaning "We have been saying ___ for an hour." The subjects spoke the list of utterances six times, each time presented in a different random order. Due to technical problems during recording and during postprocessing, there are fewer repetitions for some speakers and tokens. Overall, the design contained 57 words $\times 5$ speakers $\times 6$ repetitions $=1710$ tokens, minus data loss for 86 tokens, rendering 1624 tokens available for analysis.

The stimuli contained /, $\mathrm{r} /$ in nucleus as well as in onset and coda position, for the latter both as singleton and as part of a cluster (e.g., chlap, lob, chlp, mol, álp or mrak, rak, mrk, ker, park). Stimuli were mostly real words or common onomatopoeic expressions (bam, bum, brm). The nonwords bib, bab, bub were used for cases in which it was crucial to control for the surrounding consonant and no real words exist. Subjects were familiarized with these words prior to the recording. The Appendix gives a full list of all stimuli with an English gloss and an IPA transcription. More details on the stimuli are given in the Measurements section, since we employed different words for different types of measurements.

\subsection{Data segmentation}

Spatial and temporal characteristics of the consonantal constriction formation and release were labeled semi-automatically based on kinematic events in the articulator velocity profiles. The algorithm, developed by Mark Tiede at Haskins Labs, identifies the peak velocities of the movement into and out of a constriction, and identifies the kinematic event's movement onset (GONS), achievement of target (NONS), and release (NOFFS) on the basis of a percentage $(20 \%)$ of these peak velocities, and also identifies the maximal constriction as the point of minimal velocity between the onset and offset of the target. For the consonants, the sensor placed on the articulator performing the main constriction is labeled - TT for $/ 1, \mathrm{r} /$ and all coronals, TD for dorsals, TB1 for palatals, and LA for bilabials. For labiodentals, the vertical position of the lower lip was labeled. For the vowels and for the retraction gesture of $/ 1, r /$, the tangential velocity of TB1 or TB2 (depending on the subject and the vowel) was used for identifying the kinematic events. In EMA data, movements into vocalic constrictions can be measured by analogy to consonant movements (the same labeling algorithm is applied to the time series), at least in a labial context where the degree of lingual coarticulation between consonant and vowel is minimal (hence some of our words for assessing consonant-vowel coordination had to be nonwords, see below and Appendix). The complex velocity profile of the trill is not handled well by the labeling algorithm. All labels were carefully inspected in order to determine whether they capture comparable time- 
points in the trill, if not, the labels were eliminated. The labels identifying movement onset and peak velocity were usable for most tokens, but later kinematic events could only be identified for some of the tokens. Therefore the degrees of freedom differ in the reported statistical results for $/ \mathrm{r} /$ depending on the measure reported. A summary of the measures employed and the respective stimuli is given at the end of this section.

\subsection{Measurements}

The over-arching question we pursue is whether there is a phonetic correlate of being in the nucleus position. This is approached from two angles. For one, we investigate whether the nucleus position can be characterized kinematically. To that effect, we compare the kinematic profiles of syllabic $/ 1 /$ and $/ r /$ to their nonsyllabic counterparts in onset and coda. Secondly, we ask whether the nucleus is differentiated from the other syllable positions in terms of articulatory timing. If that is the case, the same consonant sequence should show different timing patterns depending on the syllable position occupied by the consonants. For example, a $/ \mathrm{mr} /$ sequence should be timed differently in $\underline{m r k}$ (onset-nucleus) compared to the same sequence in mrak (onset cluster). In parallel, we ask whether onsetnucleus timing is comparable for consonantal and vocalic syllables (e.g., $\underline{\text { brm }}$, $\underline{b i m})$.

2.3.1. Kinematics. For the first hypothesis, concerning possible changes in the liquids' kinematics as a function of syllable position, the following predictions can be formulated: If the nucleus position is defined kinematically, we would expect the liquids to be slower and longer (i.e. "more vocalic") in nucleus position compared to their counterparts in onset/coda position. This would be evident in terms of a longer time to peak velocity of the closing movement, a lower peak velocity and stiffness of the closing movement, and a longer plateau duration.

Plateau duration is defined as the time interval between target achievement and release, time to peak velocity of the closing movement is defined as the temporal lag between the timepoint of movement onset and the timepoint of maximal velocity of the movement into the constriction. As an indicator of stiffness we use amplitude divided by the peak velocity of the closing movement, with amplitude being defined as distance between the vertical position of the sensor at movement onset and its position at maximal constriction.

2.3.2. Timing. Measures of articulatory timing are used to examine the coordination relations in vocalic and consonantal syllables. Consonant-consonant timing is evaluated in terms of plateau lag, which is defined as the temporal lag between the release of the first consonant of the sequence and the achievement of target for 
the second consonant of the sequence. For example, we measure the temporal lag between the release of $/ \mathrm{m} /(\mathrm{C} 1)$ and target achievement for $/ \mathrm{r} /(\mathrm{C} 2)$ in both $\underline{m r k}$ and mrak. Likewise we compare the lag between the release of $/ \mathrm{r} /(\mathrm{C} 1)$ and target achievement for $/ \mathrm{k} /(\mathrm{C} 2)$ in both mrk and park. The lag is always calculated as timepoint of target achievement of $\mathrm{C} 2$ minus timepoint of release of $\mathrm{C} 1$, thus, greater lag values correspond to less overlap between the target plateaus of the two consonants. This measure is one of many possible overlap measures and is mainly informative as to whether the release of the first consonant is overlapped by the following consonant. For investigating onset-nucleus timing, we calculate the temporal lag between the onset and nucleus gestures in terms of the timepoints of peak velocity of the closing movement.

Another coordination measure pertains to the so-called C-center effect, as mentioned in Section 1.3. We measure whether vocalic and consonantal syllables exhibit a C-center effect, which has been taken to be indicative of a particular coordination relationship between the syllable nucleus and the onset consonants. A subset of our stimuli was therefore designed to test whether for Slovak increasing onset complexity conditions a temporal shift relative to a constant anchor point in the right-edge and left-edge of the onset, but not in the temporal midpoint of the onset (the C-center; see Figure 1). The timepoint of peak velocity of the closing movement for the coda consonant serves as a constant reference point. For example, for comparing the temporal lag in $m r k$ vs. smrk, the timepoint of peak velocity of the closing movement for $/ \mathrm{k} /$ is used as an anchor point. For each onset $(/ \mathrm{m} / \mathrm{in}$ $m r k$ and /sm/ in smrk) we take three measurement points, whereby 'left-edge' corresponds to the timepoint of target achievement of the first consonant in the onset $(/ \mathrm{m} /$ in $m r k, / \mathrm{s} /$ in smrk), 'C-center' is calculated as the temporal midpoint of the onset as a whole, and 'right-edge' is defined as the timepoint of release of the last consonant in the onset $(/ \mathrm{m} /$ in both $m r k$ and $s m r k)$. For each of the three measurement points, we then compare the anchor lag in mrk and smrk and use this difference between singleton and cluster as a dependent variable in our statistical tests. If the onset is coordinated to the nucleus as a single unit irrespective of the number of consonants the onset contains, we expect to see a significant difference in lag between singleton and cluster for both left-edge and right-edge, but no significant difference for the midpoint (Figure 1).

Our analyses are presented in summary in Table 1 below. For each measurement or set of measurements, the set of stimulus words is given for which these measurements were performed. We will later in the text refer to these sets of stimuli as listed here, for example as Stimulus Set 2a. Dots in bisyllabic words indicate the assumed syllabification.

For statistical analyses, we averaged across the six repetitions per word. Univariate ANOVAs with Subject as a random factor were performed, separately for $/ 1 /$ and $/ \mathrm{r} /$ unless stated otherwise. Significance is evaluated at a level of $p<.05$. For posthoc tests, two-tailed, paired-sample t-tests were run on the comparisons of interest. Where the different levels of the main factor contained an unequal number 
Table 1. Measurements and stimulus sets

$\underline{1 . \text { Kinematic measures }}$

- plateau duration

- peak velocity of the closing movement

- time to peak velocity of the closing movement

- stiffness

Stimulus Set 1 comparing liquids in onset, nucleus and coda position

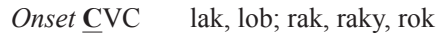

Nucleus CLC chlp, blb; mrk, krk, krb

Coda CV $\underline{\text { C }}$ kal, mol; bar, ker, mor

2a. Coordination measures: Consonant-consonant coordination

Measure plateau lag between successive consonants

Stimulus Set $2 a$ comparing $\underline{\mathbf{C C V}}$ to $\underline{\mathbf{C L C}}$ and V $\underline{\mathbf{C C}}$ to $\underline{\mathbf{L C}}^{6}$

CCV chlap, vlak, klak; mrak, krab, krok

CLC/CLC chlp, vlk, klk; mrk, krb, krk

VCC skalp, folk, kalk; park, erb, kvark

2b. Coordination measures: Onset-nucleus coordination

Measure peak velocity lag (closing movement)

Stimulus Set $2 b$ comparing onset-nucleus timing in $\underline{\mathbf{C V}}$ vs. $\underline{\mathbf{C L}}$

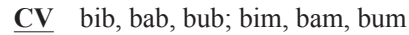

CL blb; brm

Measure $\quad$ C-center effect: Temporal lag of left-edge, midpoint, right-edge in singleton and cluster to a fixed anchorpoint

Stimulus Set $2 c \quad$ comparing anchorlag in $\underline{\mathrm{CV}}$ vs. $\underline{\mathrm{CCV}}$ and in $\underline{\mathrm{CL}}$ vs. $\underline{\mathrm{CC}} \mathrm{C}$

$C V$ vs. $C C V$

lak - vlak; lob - klop; mok.ni - zmok.ni; bo.ku - zbo.ku;

mok - smog; raky - braky; rok - krok

$C L$ vs. $C C L^{7}$

vlh.čil - zvlh.čil ${ }^{8}$; kl.čo.val - skl.čo.val; mĺk.vy - zmĺk.ni;

bí.kol - zbĺ.kol; mrk - smrk; brn.kol - zbrn.kol; krst - skrz

of words or not all measurement points could be obtained for each token (see above), the test statistics contained missing cells; hence the degrees of freedom can vary and have fractional values.

To recapitulate, if the kinematics of a consonant vary as a function of syllable position, we predict that $/ 1, r /$ in the nucleus position will show a longer plateau duration, longer time to peak velocity, and a lower stiffness. For the coordination measures our predictions depend on the results for the kinematic measures. If we find that syllabic consonants differ in their kinematics from their syllable margin counterparts, we would predict that onset-nucleus coordination is the same for vocalic and consonantal syllables. If, however, the nucleus position is not differentiated on the basis of the kinematic measures, as was found by Fougeron and Ridouane (2008) for Tashlhiyt Berber, another plausible hypothesis is that the typological dispreference for unrestricted syllabic consonants is related to differences in the coordination relations between vocalic and consonantal syllables. 
Table 2. Statistical significance patterns for the kinematic measures, Stimulus Set 1a. Statistically significant main effects are highlighted in bold face.

\begin{tabular}{|c|c|c|c|c|c|}
\hline \multirow[t]{2}{*}{ Consonant } & \multirow[t]{2}{*}{ Measure } & \multirow{2}{*}{$\begin{array}{l}\text { Main position } \\
\text { effect }\end{array}$} & \multicolumn{3}{|c|}{ Posthoc pairwise comparisons } \\
\hline & & & Nucleu-Onset & Nucleus-Coda & Onset-Coda \\
\hline \multirow[t]{7}{*}{$/ 1 /$} & $\begin{array}{l}\text { plateau } \\
\text { duration }\end{array}$ & $\begin{array}{l}\mathrm{F}(2,8)=2.45 \\
p=.15\end{array}$ & & & \\
\hline & time to peak & $F(2,8)=14.6$ & $t(9)=4.87$ & $\mathrm{t}(9)=.89$ & $\mathrm{t}(9)=7.31$ \\
\hline & velocity & $p=.002$ & $p=.001$ & $p=.4$ & $p<.001$ \\
\hline & stiffness & $F(2,8)=7.82$ & $t(7)=-3.84$ & $\mathrm{t}(7)=-1.3$ & $t(9)=-4.17$ \\
\hline & & $p=.013$ & $p=.004$ & $p=.24$ & $p=.002$ \\
\hline & peak velocity & $F(2,8)=6.2$ & $t(9)=-2.38$ & $\mathrm{t}(9)=4.94$ & $\mathrm{t}(9)=1.43$ \\
\hline & & $p=.024$ & $p=.04$ & $p<.001$ & $p=.19$ \\
\hline \multirow[t]{7}{*}{$\mid \mathrm{r} /$} & $\begin{array}{l}\text { plateau } \\
\text { duration }\end{array}$ & $\begin{array}{l}\mathrm{F}(2,8.17)=2.05 \\
p=.19\end{array}$ & & & \\
\hline & time to peak & $F(2,8)=5.02$ & $\mathrm{t}(14)=-.055$ & $t(14)=2.84$ & $\mathrm{t}(14)=3.2$ \\
\hline & velocity & $p=.039$ & $p=.96$ & $p=.013$ & $p=.006$ \\
\hline & stiffness & $F(2,8.04)$ & & & \\
\hline & & $p=.116$ & & & \\
\hline & peak velocity & $F(2,8)=41.6$ & $\mathrm{t}(14)=4.02$ & $t(14)=3.34$ & $\mathrm{t}(14)=7.04$ \\
\hline & & $p<.001$ & $p=.001$ & $p=.005$ & $p<.001$ \\
\hline
\end{tabular}

\section{Results}

\subsection{Kinematic measures}

In order to present the statistical results in a concise fashion, a table is given first, reporting the $p$-values for each ANOVA and associated posthoc t-tests (Table 2). Graphs in Figure 2 show the means and standard deviations (SD) for each measure; the whiskers show 1 SD in each direction. The ANOVAs reported in Table 2 had a single factor Position with the three levels onset, nucleus and coda. Statistically significant main effects are highlighted in bold face. Posthoc two-tailed, paired-samples t-tests were conducted only for measurements with significant main effects.

Plateau duration (Figure 2a) shows no significant main effect for either consonant. ${ }^{9}$ Figure $2 \mathrm{~b}$ displays the results for time to peak velocity, with a statistically significant main effect for both consonants. The posthoc comparisons reveal for /1/ that onset has a significantly shorter time to peak velocity than both nucleus and coda. In contrast, for $/ \mathrm{r} /$, both onset and nucleus differ significantly from coda $/ \mathrm{r} /$ but not from each other on this measure. Stiffness, shown in Figure 2c, achieves significance only for /1/. Nucleus /1/ patterns with coda /1/, with both coda and nucleus differing significantly from onset but not from each other. In terms of peak velocity (Fg 2d), for /r/ all three positions differ significantly from each other with nucleus falling between onset and coda values. Nucleus /1/ is on average slower compared to onset and coda consonants. 

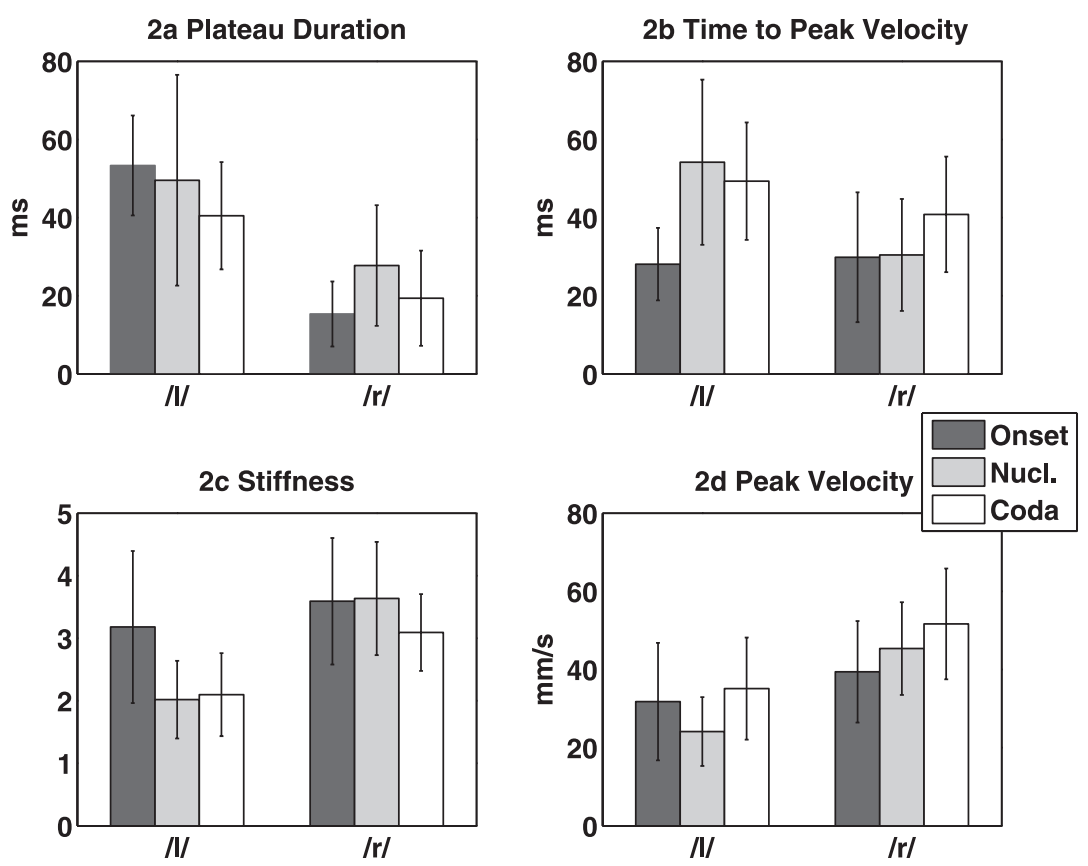

Figure 2. Kinematic measures comparing $/ l, r /$ in onset $(\underline{C} V C)$, nucleus $(C \underline{L} C)$, and coda position $(C V \underline{C})$, Stimulus Set 1. 2a) Plateau duration, 2b) time to peak velocity of the closing movement, 2c) stiffness, 2d) peak velocity of the closing movement.

Across the kinematic measures no entirely coherent picture is apparent. The patterns are quite varied for the two consonants and the different measures. Regarding the overall qualitative trend in the data, it can be said that $/ r /$ in nucleus position has, compared to the other two syllable positions, a longer plateau duration, as well as comparable (time to) peak velocity and stiffness values to onset (with a tendency to be faster than onset). Compared to onset position /1/ in the nucleus shows a longer time to peak velocity, a lower stiffness and peak velocity, and no clear difference in plateau duration. While syllabic $/ 1 /$ and $/ \mathrm{r} /$ therefore differ from their counterparts in onset and coda positions, differences in their kinematics are overall rather subtle, and can be in either direction across subjects. For the significant main effects, nucleus / $1 /$ has a tendency to be more similar to coda than to onsets (time to peak velocity, stiffness) while nucleus $/ \mathrm{r} /$ is arguably somewhat more similar to onset (time to peak velocity). It should also be kept in mind that under corrections for multiple comparisons, the nucleus effects should mostly not be considered significant, and the bulk of the statistical significance is contributed by onset-coda differences. In short, there is no overall pattern that would unambiguously support a kinematic definition of the nucleus position. 
We conclude from this part of the analysis that phonological status as syllable nucleus does not fundamentally affect the phonetic properties of /1/ and /r/. Syllabic consonants in Slovak are phonetically consonants in terms of their kinematics in that on many measures they are not different from their counterparts in onset and/or coda position. We now turn to our second set of measures pertaining to the temporal coordination relationships in consonantal versus vocalic syllables.

\subsection{Coordination measures}

The measurements presented in this section concern consonant-consonant and consonant-vowel coordination. The research question addressed is whether the articulatory coordination of the onset and coda consonants with respect to a vocalic nucleus differs from the articulatory coordination for consonantal syllables. In this analysis, we compare the timing of identical consonant sequences under variation in syllable position (Table 1, Stimulus Set 2a). For example, we compare the consonant-consonant timing for $/ \mathrm{mr} /$ in mrak (onset cluster) to the timing of the same sequence in $\underline{\boldsymbol{m} \boldsymbol{r}}$ (onset-nucleus). For coda, we compare /rk/ timing in $m \underline{r k}$ (nucleus-coda) to the timing of the same sequence in park (coda cluster). Results are shown in Figure 3.

The pattern is very consistent: For both / $/$ and / $/$, consonant sequences containing a syllabic consonant (white bars in Figure 3) have greater plateau lags, and are thus less overlapped, compared to onset/coda clusters (dark bars in Figure 3). Comparing the values across the left-hand and right-hand graphs of Figure 3, consonant sequences in the left panel (onset cluster, onset-nucleus) show a greater lag than the consonant sequences in the right panel (coda clusters, nucleus-coda).
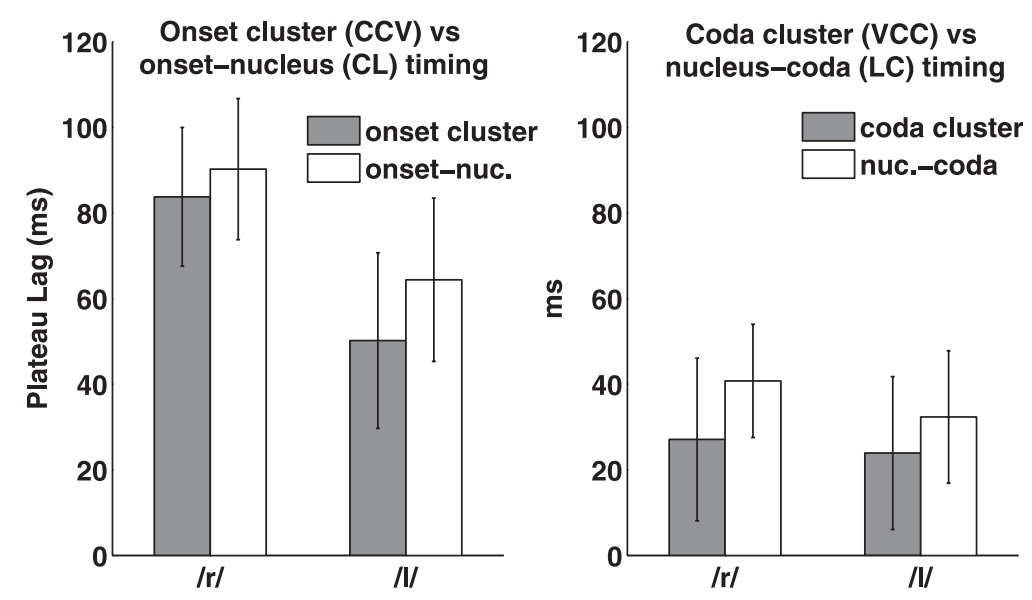

Figure 3. Plateau lag in consonant sequences. Left panel: Plateau lag for onset cluster and onsetnucleus sequences. Right panel: Coda cluster and nucleus-coda sequences. Stimulus Set $2 a$. 
CCV onset clusters (dark bars in the left-hand graph) show a greater lag than VCC coda clusters (dark bars in right-hand graph). Likewise the CL onset-nucleus lag (white bars in left-hand graph) is considerably greater than the LC nucleus-coda lag (white bars in right-hand graph). An ANOVA with the single factor Cluster Type, containing the four levels CCV, CL, LC and VCC was conducted. The main effects were significant for both $/ \mathrm{l} /$ and $/ \mathrm{r} /$. All posthoc tests reached significance except for CCV-CL for /r/ and for VCC-LC for /1/ (details for /1/: $\mathrm{F}(3,12)=7.67$, $p=.004$, posthoc CCV-CL $p=.025, \mathrm{VCC}-\mathrm{LC}: p=.097, \mathrm{CCV}-\mathrm{VCC} p<.001$, $\mathrm{CL}-\mathrm{LC} p<.001$; for $/ \mathbf{r} /: \mathrm{F}(3,12.5)=60.04, p<.001$ posthoc: $\mathrm{CCV}-\mathrm{CL} p=.08$, VCC-LC: $p<.016$; CCV-VCC $p<.001 ;$ CL-LC $p<.001)$.

Summarizing the results so far, we observe that a sequence of two consonants shows different timing patterns depending on the syllable position of these two consonants. If one of the consonants is in the nucleus $(\underline{\mathbf{C L}} / \mathbf{L C})$, plateau lags are greater than if both consonants are in onset or coda ( $\underline{\mathrm{CV}} / \mathrm{VCC})$. Timing in consonantal syllables therefore differs systematically from cluster timing in vocalic syllables. Yet the strongest effect is the difference between onset and coda clusters of vocalic syllables ( $\underline{C}$ V vs. VCC, dark bars in left/right graphs of Figure 3), with a parallel effect for differences between $\underline{\mathbf{C L}}$ and $\underline{\mathbf{L C}}$ (white bars in left/right graphs of Figure 3). Importantly, the fact that onset-nucleus (CL) timing differs significantly from nucleus-coda (LC) timing provides evidence for the presence of syllabic organization in consonantal syllables; CLC syllables are not just concatenations of consonants without further internal structure. Another point to note is that due to onset clusters and CL sequences showing a greater plateau lag compared to coda clusters and LC sequences, the $\mathrm{C}-\mathrm{C}$ transitions to the left of the nucleus are "more open" in the sense of Catford (1977) than the comparable transitions to the right of the nucleus, and often result in so called transitional schwas. This point will be taken up again in Section 4.

As a next step, we compare onset-nucleus coordination in vocalic syllables and consonantal syllables based on Stimulus Set $2 \mathrm{~b}$ in Table 1 . We assess the coordination relation by means of the peak velocity lag of the constriction formation gestures for onset and nucleus (Table 2). For example, we compare the peak velocity lag between $/ \mathrm{b} /$ and $/ \mathrm{l} /$ in $\mathrm{blb}$ to the peak velocity lag between $/ \mathrm{b} /$ and a following vowel (e.g., bib). A univariate ANOVA with the fixed factor Vowel (levels: /i, a, u/) testing for peak velocity lag differences among the vowels was not significant $(\mathrm{F}(2,8)<1, p=.66)$. Therefore we collapse across the three vowel conditions in the following analysis. Table 3 shows that vocalic syllables show the shortest peak velocity lag, while syllabic /r/ has the biggest lag. Statistically, /r/ differs significantly from the vocalic syllables, / $1 /$ shows a difference at trend level. $/ 1 /$ and $/ \mathrm{r} /$ nuclei also differ significantly from each other. This confirms that the onsetnucleus coordination relationship within a syllable varies systematically as a function of the syllable nucleus being a consonant or vowel, but also the identity of the consonantal nucleus plays a role (paired samples t-tests: $\mathrm{V}-/ \mathrm{r} /: \mathrm{t}(4)=8.27 p=.001$; $\mathrm{V}-/ \mathrm{l} / \mathrm{t} \mathrm{t}(4)=2.51 p=.067 ; / \mathrm{l} /-/ \mathrm{r} /: \mathrm{t}(4)=-6.81 p=.002)$. 
Table 3. Onset-nucleus peak velocity lag as a function of nucleus type

\begin{tabular}{lrr}
\hline Nucleus type & \multicolumn{2}{c}{ Peak velocity lag (ms.) } \\
\cline { 2 - 3 } & \multicolumn{1}{c}{ mean } & SD \\
\hline vowel & 82.52 & 23.68 \\
/l/ & 106.36 & 16.37 \\
r $/$ & 151.91 & 10.17 \\
\hline
\end{tabular}

Table 4. Cluster singleton ratio of the anchor lag for the three measurement points left-edge, midpoint, and right-edge

\begin{tabular}{lrrr}
\hline Measurement Point & \multicolumn{3}{c}{ mean (SD) anchor lag ratio nucleus type } \\
\cline { 2 - 4 } & \multicolumn{1}{c}{$/ \mathrm{l} / \mathrm{r} /$} & $\mathrm{V}$ \\
\hline Left-edge & $1.46(.21)$ & $1.48(.32)$ & $1.90(.48)$ \\
Midpoint & $1.24(.13)$ & $1.26(.24)$ & $1.50(.27)$ \\
Right-edge & $.93(.10)$ & $.96(.18)$ & $.95(.13)$ \\
\hline
\end{tabular}

Finally, we present the results for the C-center measure (Table 1, Stimulus Set 2c), which allows us to assess the coordination of simplex and complex onsets to the nucleus. Recall that for this measure, we compare whether the temporal distance of various measurement points in the onset (left-edge, midpoint, right-edge) to a fixed anchorpoint changes as a function of syllable complexity. For example, we compare the anchor lag of the three measurement points for the $/ \mathrm{m} /$ onset in $m r k$ to the anchor lag of the same measurement points for the / sm/ onset in smrk, and analogously for the $/ \mathrm{m} /, / \mathrm{sm} /$ onsets in mok, smog. In Table 4, we report the differences in anchor lag between the singleton and cluster conditions as ratios. The ratio was calculated by dividing the anchor lag in the cluster condition by the anchor lag in the singleton condition. A value $<1$ indicates a shift towards the anchorpoint, while a value $>1$ indicates a shift away from the anchorpoint. A value of 1 means the relative timing between consonant and anchor has not changed between conditions. The prediction of $\mathrm{C}$-center theory therefore is that the midpoint measurement point should have a ratio of close to 1. As can be seen in Table 4 , it is instead the right-edge of the onset (release of the vowel adjacent consonant) that changes least in its timing between conditions.

Statistically, we first investigated whether there is a significant difference between the three nucleus types. To that effect, we evaluated the ratios using a repeated measures ANOVA, one for each measurement point, with the single factor Nucleus with the levels $/ 1 /, / \mathrm{r} /$ and $\mathrm{V}$. The results were as follows: Left-edge $\mathrm{F}(2,8)=17.35, p=.001$; midpoint $\mathrm{F}(2,8)=18.87, p=.001$; right-edge $\mathrm{F}(2,8)<1$, $p=.6$. Looking at Table 4 , it can be inferred that the significant main effect for left-edge and midpoint stems from $/ 1, \mathrm{r} /$ differing from the vowel but not from each other. To statistically validate this observation while keeping repeated statistical 
Table 5. T-test results for the anchor lag comparison between singleton and cluster conditions for the three measurement points.

\begin{tabular}{lccccc}
\hline Measurement Point & \multicolumn{2}{c}{ vocalic nucleus } & & \multicolumn{2}{c}{ consonantal nucleus } \\
\cline { 2 - 3 } & $\mathrm{t}(4)$ & $p$ & & $\mathrm{t}(4)$ & \\
\hline Left-edge & 8.5 & .001 & 6.80 & .002 \\
Midpoint & 6.93 & .002 & & 3.72 & .02 \\
Right-edge & -1.46 & .22 & & -1.08 & .34 \\
\hline
\end{tabular}

testing to a minimum, two paired-sample t-tests were conducted as posthocs, comparing the ratios of $/ 1 /$ and $/ \mathrm{r} /$ for midpoint and left-edge. The tests failed to reject the null hypothesis, confirming that the significant main effect stems from $/ 1, \mathrm{r} /$ differing from the vowel conditions (midpoint $\mathrm{t}(4)=-1.52, p=.2$; left-edge $\mathrm{t}(4)=$ $-1.09, p=.34)$.

Next we ran a series of paired-sample t-tests on the anchor lag, contrasting anchor lag in the singleton and cluster conditions. This analysis collapses across /1, r/ nuclei, since the previous analysis revealed no statistically significant difference between the liquids. A test was run for each measurement point (left-edge, midpoint, right-edge), separately for consonantal and vocalic syllables. Table 5 gives the $\mathrm{t}$ - and p-values for each test. Under a C-center effect, cluster and singleton lags should be identified as coming from the same distribution for the midpoint measurement (non-significant difference), but not so for the left-edge or right-edge (significant difference, see Marin and Pouplier 2010). These statistical results confirm that for both nucleus types, it is the right-edge that shows no significant difference between the singleton and cluster conditions.

Summing up the results of this section, we conclude that firstly, both vocalic and consonantal syllables showed a significant difference in timing for left-edge and, unexpectedly, for midpoint measurements. For both syllable types, right-edge was the measurement point that changed least between the singleton and cluster conditions, that is, the timing of the release of the prevocalic consonant to the anchor lag (right-edge) remained the same across conditions. This means that as more consonants are added to the onset, these consonants are coordinated sequentially to the left of the nucleus. However, vocalic and consonantal syllables differed significantly from each other in the size of the effect. Vocalic syllables show a greater anchor lag ratio (and thus greater change between the singleton and cluster conditions) compared to the consonantal syllables.

\section{Discussion and conclusion}

At the outset of our study we hypothesized that the cross-linguistic dispreference for unrestricted syllabic consonants may be articulatorily grounded. If vowels and 
the vowel cycle are fundamental to the articulatory coordination of consonants within a syllable, and consonants ride on continuous vowel articulations, consonantal nuclei with a complex syllable structure might be typologically rare because they do not afford the same coordination relationships that vowels allow for. For languages that do license unrestricted syllabic consonants, we hypothesized that the phonetic correlate of the nucleus position may therefore be a more vowel-like articulation of the consonants. Given that syllable structure is expressed in articulatory timing, we further pursued the possibility that the signature difference of syllabic consonants may lie in their timing relationships with onset/coda consonants. In terms of the intrinsic kinematic properties of the consonantal gesture, we found overall no consistent effect of nucleus position on consonantal kinematics: On some measures syllabic consonants patterned with onsets, on some with coda consonants. Syllabic consonants do not change their kinematics fundamentally to approximate more vowel-like articulations; they clearly retain their consonantal identity. This finding is also in agreement with the Fougeron and Ridouane (2008) study. Overall, our results suggest that consonantal syllables are essentially consonant clusters.

Yet our results likewise underscore that consonantal syllables are not just sequences of consonants without any further internal structure. Indeed, the most consistent differences for consonantal syllables became evident in the timing measures, echoing the work of Krakow and others on the syllable as the domain of articulatory timing (Krakow 1999). In terms of the coordination relationships, we compared $\underline{\mathbf{C L}}$ and $\underline{\mathbf{L C}}$ timing to $\underline{\mathbf{C V}}$ and VCC consonant clusters as well as to onset-nucleus (CV vs. CL) timing in vocalic and consonantal syllables. In terms of consonant-consonant timing, for both syllable types onset cluster/CL consonant sequences are less overlapped compared to coda cluster/LC consonant sequences. In addition, CL and LC show generally a greater plateau lag compared to onset and coda clusters in vocalic syllables. That is, consonants in consonantal syllables are less overlapped compared to consonants in vocalic syllables. Fougeron and Ridouane (2008) also found in their study on Tashlhiyt Berber that nuclei are less overlapped by a preceding consonant than by a following consonant. Further, our data provide evidence that in CLC syllables, the consonants at the syllable edge are coordinated with respect to the consonantal nucleus: Onset-nucleus and nucleuscoda coordination in consonantal syllables differ significantly from each other and pattern in the same way as $\underline{\mathbf{C V}}$ and VCC differences in vocalic syllables. Therefore, syllabic consonants constitute a syllable nucleus in terms of coordination relations, even though the coordination relations differ from the one in clusters of vocalic syllables. This is further evident in that onset-nucleus coordination is systematically different for consonantal and vocalic syllables. Thus overall, onsetnucleus consonant sequences show a significantly greater lag value compared to $\underline{\mathbf{C C V}}$ onset clusters as well as compared to $\underline{\mathbf{C V}}$ onset-vowel timing.

Given these findings on the temporal/coordination basis of consonantal syllables, our investigations of the $\mathrm{C}$-center effect rendered unexpected results. For one, 
overall consonantal and vocalic syllables patterned alike in that for both syllable types, right-edge anchor lag did not differ significantly across conditions. Consonantal syllables with $/ 1, \mathrm{r} /$ nuclei differed from vocalic syllables in the size of the timing differences between conditions; midpoint and left-edge ratios differ for $/ 1, \mathrm{r} /$ versus vocalic syllables.

The C-center measure has been taken to be the surface manifestation of quite specific underlying phase relationships: Onset consonants are by hypothesis coordinated anti-phase with each other, but in-phase to the vowel. For CV syllables, these phase relationships result in a near-simultaneous articulation of the onset and the nucleus, and it is due to the different dynamic parameterization of the onset and nucleus that the vowel extends in time beyond the duration of the onset (Löfqvist and Gracco 1999). In CCV syllables, the anti-phase CC and in-phase CV phasing relationships are incompatible in that the requirement for two consonants to be simultaneously in-phase with the nucleus and anti-phase with each other cannot be satisfied at the same time. The compromise output of these competing phasing relationships is the $\mathrm{C}$-center effect, with the surface characteristic of a shift of the prenuclear consonant into the vowel and the stability of the C-center (Browman and Goldstein 2000).

Our data do not show C-center stability for either vocalic or consonantal syllables, instead, the right-edge of the onset shows least variability across conditions. It has been argued that in-phase coordination is universally preferred in action systems (Kelso 1995), and that the cross-linguistic preference of the CV syllable is a linguistic exploitation of this preference (Goldstein et al. 2006; Nam et al. 2009). Our results would then imply that onset clusters are generally not coordinated inphase with the nucleus in Slovak. However, recent work also suggests that there may be a systematic interaction between syllable-position specific timing and other factors known to impact timing such as the internal composition of clusters (place of articulation, voicing, compensatory shortening effects etc.). For example, in a recent study Shaw and colleagues (in press) have modeled computationally how the interaction of multiple timing effects may condition variable consonantconsonant timing on the surface and come to hide an underlying C-center effect. Yet our results are not characterized by unexpected variability, they are indeed quite consistent for both vocalic and consonantal syllables; they both show the same pattern. At least for the clusters investigated here, Slovak therefore seems to show an onset coordination pattern that is not predicted by the C-center hypothesis. ${ }^{10}$ Also, identifying which coordination relationships specifically underlie the data presented here will have to be addressed in future research. To come back to our introductory observation, while there are certainly strong cross-linguistic preferences, exceptionless linguistic universals are hard to come by. Grammar has a stabilizing function, and universals mostly have the status of statistical tendencies rather than absolutes. It may thus very well be the case that languages may phonologize a greater variety of timing patterns than has been thought possible so far. 
We now return to the question we had at the outset of our study: What makes freely distributed syllabic consonants typologically dispreferred? Our measures have revealed that consonantal nuclei are different from vocalic nuclei phonetically in that they are consonants; consonantal syllables are consonant clusters. They are, however, timed differently from consonant sequences in the syllable margin (onset/ coda clusters). Importantly, even though the timing relationships differ for consonantal and vocalic syllables, there still is evidence for coordination of the syllable margins to the nucleus position in consonantal syllables. Onset-nucleus timing differed significantly from nucleus-coda timing for CLC syllables. Consonant timing may be the key then to understanding the phonotactic phenomenon of syllabic consonants; syllabic consonants are less overlapped. This does not answer the question of why some languages would allow these specific relatively less overlapped coordination relationships that are characteristic of syllabic consonants (assuming our findings generalize beyond Slovak, see below), while others do not. For Slovak, it is worth noting that consonant sequences involving $/ 1 /$ and $/ \mathrm{r} /$ are timed rather far apart generally, ${ }^{11}$ and we see a sonorant portion in the oscillogram preceding the trill, similar to an open transition schwa. An example for the words $k r b$ and $k r a b$ is given in Figures $4 \mathrm{a}$ and $4 \mathrm{~b}$. For syllabic consonants the reduced overlap provides a strongly sonorant portion resulting in a significant modulation of the signal towards the nucleus (Figure 4a). This can be interpreted as there being rising sonority towards the nucleus even though the nucleus is a consonant. Note, however, that this open transition is also observed in onset clusters, which is at odds with the idea of sonority rising linearly towards the nucleus (which is of course the case for many other syllables as well, consider for instance any sibilant + stop onset cluster). Figure $4 \mathrm{~b}$ shows that if a lexical vowel is present, that vowel is still a lot more sonorous than the signal modulation arising as a by-product of the open transition.

We observe that this schwa is in fact related to a tongue body retraction gesture characteristic for liquids. In Slovak, the lateral is a 'dark' /1/, having both a tongue tip raising as well as a posterior retraction gesture. Apical trills have also been described as requiring a retraction of the tongue dorsum (Kavitskaya et al. 2009; Proctor 2009), and this is confirmed by our data: Preceding the apical gesture for /r/, we observe a marked horizontal retraction of the tongue dorsum. These less constricted gestures are known properties of liquids and have also been termed vocalic gestures due to their similarity to vowels in terms of tongue body control (Giles and Moll 1975; Sproat and Fujimura 1993; Krakow 1999). Unfortunately, our stimuli are not designed to evaluate the behavior of the retraction gesture systematically (mostly because surrounding velars do not allow us to reliably identify the retraction gesture), therefore we report some qualitative observations as part of the discussion here and intend to address this issue in more depth in future research.

In terms of onset-nucleus timing, the retraction gesture of liquids indeed seems to pattern in a vowel-like fashion. The tongue body gesture for / $/$ / even shows 

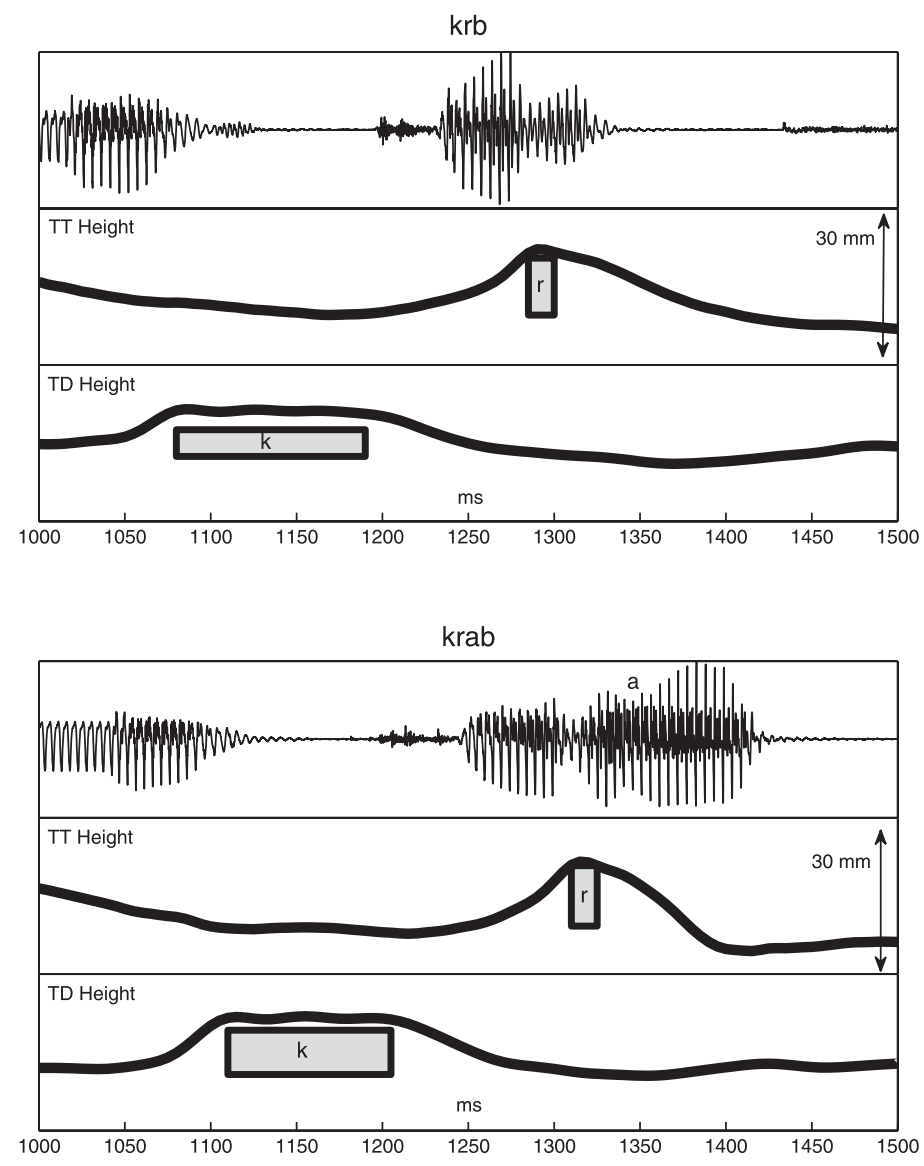

Figure 4a, b. Examples of the utterance $\mathrm{krb}$ and $\mathrm{krab}$ from subject SLS5 illustrating typical renditions of $\underline{\boldsymbol{C C}} V$ and $\underline{\boldsymbol{C L}}$ consonant timing with an open transition between the dorsal gesture and the apical gesture for $|r|$. The EMA signal time series show tongue tip height and tongue dorsum height. The boxes indicate the target plateaus for each consonant as identified by the labelling algorithm (NONS-NOFFS interval). The vowel for krab is informally indicated in the oscillogram.

slightly more onset-nucleus overlap compared to vowels; the retraction gesture of /r/ shows somewhat less overlap but is still similar to the onset-nucleus timing of a vowel. This means that the retraction gesture happens during the relatively large plateau lag that we observe in $\mathbf{C C V}$ and $\mathbf{C L}$ consonant sequences, and plays a part in providing a sonorous transition from onset to nucleus (cf. Figure 4). One could argue that phonetically it is these retraction gestures that provide a sonority peak for vowel-less syllables, and it is largely because of the retraction gesture that 
these syllables are in accordance with the sonority hierarchy (see also Proctor 2009), and that the retraction gesture provides phonetically the vocalic nucleus that is seemingly missing at the phonological level.

However, the interpretation of the open transition and the role of the retraction gesture is not so straightforward. Firstly, as mentioned above, the open transition is observed for syllabic consonants as well as for onset clusters. This speaks against the simplest interpretation of the open transition/retraction providing phonetically a vocalic syllable nucleus; we would be forced to argue, against everything we know about Slovak phonology, that words like krab contain two syllables. Secondly, it has to be kept in mind that it is the timing between the onset consonant and the nuclear tongue tip gesture that provides the sonority peak: Without the substantial plateau lag between the onset consonant and the tongue tip gesture of the liquid, the retraction would not have the acoustic effect that it has. Nonetheless, it is a very interesting question whether the retraction gesture is a crucial ingredient for syllabic consonants in Slovak. One possible indicator for such a state of affairs would be a change in the timing relationship between the retraction and the apical gesture as a function of syllable position. We would then expect the inter-segmental lag for these two gestures to be greater in nucleus position to provide a maximally sonorous interval leading up to the syllable nucleus. To the extent possible with our data, we compared the timing of the tongue tip and retraction gestures for /1/ and $/ \mathrm{r} /$ when they are part of a cluster in a CCV syllable to their timing when they are in the nucleus (stimuli mrk and mrak for three of our subjects). The preliminary results indicate that the timing of the two gestures of $/ \mathrm{r} /$ and $/ 1 /$ to each other does not change as a function of syllable position, the retraction and tongue tip gestures cohere (their timing is stable) independently of whether they are in the onset or in the nucleus (coda timing is unknown). If the retraction and the apical gesture are stable in their timing, and there is, for a syllabic consonant, a greater plateau lag between a preceding consonant and the apical gesture (see Figure 3), then again it is the timing between the onset and the coordinative structure of tongue body and tongue tip gestures as a whole that determines the acoustic properties of the onsetnucleus transition.

A further aspect to consider is the length alternations which are part of Slovak nucleus phonology. The phonological length alternations unambiguously target the apical gesture (our stimuli are not designed to test what happens to the retraction gesture when the nucleus is long). We recorded a couple of near-minimal pairs with short and long syllabic consonants for our data (klb - chlp, míkvy - plnka, frkal-frklo, vrby-vrbov), for which we can compare the length for long and short nuclear liquids. The apical gesture of a long liquid has between 1.2 and 1.8 times the duration of the gesture for a short liquid in the nucleus, which is within the range of commonly observed long-short ratios for vowels in Slovak (Beňuš and Mády 2010). Also for trills, for which the articulatory duration measurements are problematic, we identify a clear difference in duration of the apical gesture both auditorily and based on visual inspection of the spectrogram. This shows that the 
phonological length alternations affecting nuclei are realized in the consonantal gesture of the nucleus. Clearly, the consonantal and the more 'vocalic' retraction gesture are both part of the nucleus, they form together a syllabic consonant. In sum, while the fact that liquids have a retraction gesture may be intimately related to their ability to function as syllabic consonants in many languages, our data show that it is the consonant as a whole that functions as syllable nucleus phonologically and phonetically.

Generally it should also be kept in mind that while liquids are common syllabic consonants, also commonly nasals or less commonly so obstruents can be syllabic in other languages, and these consonants do not have a vocalic retraction gesture. Bell (1970) reports that statistically nasals are preferred as syllabic consonant over liquids, which is surprising from a sonority perspective. Note that this observation applies to syllabic consonants of all types, whether predictable or relatively unpredictable. The work of Krakow $(1993,1999)$ has shown that the velum gesture behaves in its syllable-position specific timing similar to the retraction gesture of /1/. For obstruents, though, the argument becomes more difficult (cf. the Fougeron and Ridouane [2008] study of syllabic/k/ in Tashlhiyt Berber). We can speculate at this point that the cross-linguistic preference for nasals and liquids as syllabic consonants may be related to these consonants having two gestures, one of which is kinematically "consonantal" while the other is kinematically more "vocalic," but this clearly has to remain an issue for future research. While the retraction gesture of liquids is probably part of the explanation of how Slovak can enable vowel-less words, it can provide typologically only a partial explanation.

It seems to us then, that the most general conclusion we can come to is that the signature difference of consonantal syllables lies in the coordination relationships rather than in the kinematic parameterization of the syllabic consonant. Consonant timing appears to be related to the patterning of syllabic consonants in a language, and thus to a language's phonotactics. Sonority can be regarded phonetically as a modulation of the signal (Ohala and Kawasaki-Fukumori 1997), and, as argued above, a "wide" timing of the consonants is one way of providing such a modulation in the absence of a vowel. Therefore languages that time their consonants far apart provide a favorable environment for syllabic consonants to emerge. It is known that there are systematic cross-language differences in consonant timing: Korean, for example, shows a much higher degree of overlap than English, while Russian shows less overlap (Zsiga 2000, 2003; Kochetov et al. 2007). Arabic and Tashlhiyt Berber can time their consonants far apart; in some instances this may lead to an open transition schwa (Dell and Elmedlaoui 1988, 2002; Gafos 2002). Gafos, in his analysis of Arabic, has presented forceful arguments for a close relationship between morphological alternations and consonant timing in Arabic (Gafos 2002). In our view, syllabic consonants in Slovak and other languages present evidence that the phonotactic patterning of consonants in a language is tightly interwoven with consonant timing. We would like to argue that there is an implicational relationship between phonotactics and consonant timing such that the 
systematic presence of unrestricted syllabic consonants in a given language implies that this language will feature a low degree of overlap in consonant sequences.

\section{Acknowledgments}

Work supported by DFG grant PO 1269/1-1 to Marianne Pouplier and a Humboldt fellowship to Štefan Beňuš at the Institute of Phonetics in Munich. The second author also gratefully acknowledges support from the EU project CRISIS (ITMS 26240220060). We would like to thank our colleagues in Munich and the LabPhon 12 audience for valuable discussions and feedback. We are also much indebted to Simone Beg for subject recruitment and invaluable help with data analysis.

\section{Appendix}

List of stimuli with English glosses and IPA transcriptions. Syllabification is indicated by a period; syllabic consonants are marked in the IPA transcription. * Denotes prefixal word-initial sibilants (see note 4).

$\begin{array}{lll}\text { Word } & \text { Gloss } & \text { IPA } \\ \text { Álp } & \text { Alps-Gen.Pl. } & \text { a:lp } \\ \text { bab } & \text { nonword } & \text { bab } \\ \text { bam } & \text { onomatopoeic } & \text { bam } \\ \text { bar } & \text { bar-Nom.Sg } & \text { bar } \\ \text { bib } & \text { nonword } & \text { bib } \\ \text { bim } & \text { onomatopoeic } & \text { bim } \\ \text { bí.kol } & \text { was ablaze } & \text { bl:kol } \\ \text { blb } & \text { stupid guy } & \text { bḷ } \\ \text { bo.ku } & \text { side-Gen.Sg. } & \text { boku } \\ \text { bra.ky } & \text { rubbish-Nom.Pl. } & \text { braki } \\ \text { brm } & \text { onomatopoeic } & \text { brm } \\ \text { brn.kol } & \text { he was strumming } & \text { brykol } \\ \text { bub } & \text { nonword } & \text { bub } \\ \text { bum } & \text { onomatopoeic } & \text { bum } \\ \text { chlap } & \text { man-Nom.Sg. } & \text { xlap } \\ \text { chlp } & \text { hair-Nom.Sg. } & \text { xlp } \\ \text { erb } & \text { coat of arms-Nom.Sg. } & \text { crb } \\ \text { folk } & \text { folk-Nom.Sg. } & \text { fəlk } \\ \text { kal } & \text { sludge-Nom.Sg. } & \text { kal } \\ \text { kalk } & \text { calque-Nom.Sg. } & \text { kalk } \\ \text { ker } & \text { bush-Nom.Sg. } & \text { ker } \\ \text { kl.čo.val } & \text { he was grubbing } & \text { klt floval } \\ \text { Klak } & \text { Geographic name } & \text { klak }\end{array}$




\begin{tabular}{|c|c|c|}
\hline klk & villus-Nom.Sg. & $\mathrm{kl} \mathrm{k}$ \\
\hline klop & knock-Nom.Sg. & klop \\
\hline krab & crab-Nom.Sg. & krab \\
\hline $\mathrm{krb}$ & fireplace-Nom.Sg. & $\mathrm{krrb}$ \\
\hline krk & neck-Nom.Sg. & krk \\
\hline krok & step-Nom.Sg. & krok \\
\hline krst & babtism-Nom.Sg. & krst \\
\hline kvark & quark-Nom.Sg. & kvark \\
\hline lak & polish-Nom.Sg. & lak \\
\hline lob & lob-Nom.Sg. & $10 b$ \\
\hline mí.kvy/mík.vy & silent-Nom.Sg.Masc. & mli:kvi \\
\hline lok & liquid-Nom.Sg. & mok \\
\hline o.kni/mok.ni & get wet-Imper.Imperf. & mokni \\
\hline ol & minor-Nom.Sg. & mol \\
\hline or & plague-Nom.Sg. & mor \\
\hline Irak & cloud-Nom.Sg. & mrak \\
\hline $\mathrm{rk}$ & wink-Nom.Sg. & mrk \\
\hline park & park-Nom.Sg. & park \\
\hline ak & crayfish-Nom.Sg. & rak \\
\hline ra.ky & crayfish-Nom.Pl. & raki \\
\hline rok & year-Nom.Sg. & rok \\
\hline skalp & scalp-Nom.Sg. & skalp \\
\hline skl.čo.val* & he has deforested & 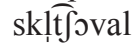 \\
\hline skrz & through & skṛz \\
\hline smog & smog-Nom.Sg. & smog \\
\hline smrk & sniff-Nom.Sg. & smrk \\
\hline vlak & train-Nom.Sg. & vlak \\
\hline vlk & wolf-Nom.Sg. & vllk \\
\hline vlh.čil & he was damping & vḷxt \\
\hline zbĺ.kol* & became ablaze & $\mathrm{zbl}: \mathrm{kol}$ \\
\hline zbo.ku* & from the side & zboku \\
\hline zbrn.kol* & he strummed & zbrinkol \\
\hline zmí.kni/zmík.ni* & shut up-Imper. & zml:kni \\
\hline .kni/zmok.ni* & get wet-Imper.Perf. & zmokni \\
\hline lh.čil* & he damped & zvḷxtfil \\
\hline
\end{tabular}

Correspondence e-mail address: pouplier@phonetik.uni-muenchen.de

\section{Notes}

1. While many assume that the syllable itself also has universal status, this view has been challenged on the basis of languages such as Gokana or Bella Coola (see Hyman 2008 for an overview). 
2. In rhotic dialects of English, words like yearn are sometimes considered to contain a syllabic consonant, and these syllabic consonants would then not be postlexically predictable. However, there still is a qualitative difference with the syllabic consonants of a language like Slovak since in English syllabic consonants do not pair with vowels in phonological alternations (see section on Slovak syllabic consonants). Whether these syllabic consonants of English should be considered as consonants at all or rather as vowels remains an open empirical issue.

3. Exceptions are onomatopoeic expressions, e.g. $b r / b \dot{r}$ for 'cold' or $k \dot{r}$ for 'frog sound', but these are truly exceptional.

4. In Slovak, $/ \mathrm{s} /, \mid \mathrm{z} /$ and $/ \mathrm{v} /$ in onset clusters can come from three sources irrespective of whether the syllable nucleus is a vowel or a consonant: 1) They arise through clitization of prepositions. Hence a separate word prosodically connects to the following noun to form a single prosodic word, such as in s tlakom [stl] 'with pressure', v tlaku [ftl] 'in pressure.' 2) They can also arise through prefixation in many productive word-formation processes, especially for forming the perfective aspect of verbs (e.g. tlačit' [tl] 'to press', stlačit' [stl] 'to push down', vtlačit' [ftl] 'to press in, imprint'). 3) They can form a consonant cluster that is not further decomposable (strom [str] 'tree', stip [st] 'post'). In many cases, it is difficult to categorize a word conclusively as either $\# 2$ or \#3. Either way, these clusters are phonologically fully incorporated (e.g., in terms of voicing agreement constraints) and these word-initial consonant sequences are therefore considered to be true clusters. For example, in the case of smrt' 'death' there is a stem mrtv meaning the same thing (mritvy 'dead', mŕtvola 'corpse'), but there is no separate word *mrt' without the initial /s/. Seemingly similar to smrk, $m r k$ is a word, but $m r k$ and smrk are not cognates: mrk means 'a wink' while smrk is connected to nose sounds (like sniffle, or nose-blowing).

5. As a sidenote, Bell (1970) identifies a length contrast in syllabic consonants to be particularly rare.

6. Due to sonority constraints, it is not possible to have the same consonant sequence in onset/coda and to the left and to the right of the nucleus (i.e., $-m r$ is not a coda cluster of Slovak).

7. In the $\mathrm{CV}$ vs. $\mathrm{CCV}$ set, only one onset cluster could be considered to be morphologically complex (zboku), but in the CL vs. CCL set in 5 out of 7 of the initial consonants in the CCL words are a prefix. Since in consonantal syllables $/ 1, \mathrm{r} /$ are nuclei and thus not available for cluster formation, many consonantal syllables with complex onsets are sibilant initial.

8. Due to regressive voicing assimilation, $<\mathrm{h}>$ in these two words corresponds to [x].

9. The plateau duration data for $/ \mathrm{r} /$ for all conditions have to be treated with care due to the difficulties associated with labelling such a dynamic articulation. The results presented show reliable differences between the conditions, but these differences are only representative of a part of the data. See Section 2 for details on $/ \mathrm{r} /$ segmentation.

10. As pointed out earlier, most of the CCL clusters involve prefixes, while for CCV clusters, only a minority of clusters involve prefixes. CCL clusters are also mostly sibilant initial. Since we found the same pattern for vocalic and consonantal syllables, however, it is unlikely that the prefixorigin of the CCL clusters has conditioned the results.

11. We also recorded a small set of obstruent CCV clusters (e.g., tká, $d b a l$ ), and these show a shorter plateau lag compared to $\mathrm{ClV}$ and $\mathrm{CrV}$ clusters.

\section{References}

Bell, Alan. 1970. Syllabic consonants. Working papers on language universals (Stanford University) 4. B1-B49.

Bell, Alan. 1978. Syllabic consonants. In Joseph Greenberg (ed.), Universals of human language, Vol. 2: Phonology, 153-201. Stanford: Stanford University Press.

Beňuš, Štefan \& Katalin Mády. 2010. Effects of lexical stress and speech rate on the quantity and quality of Slovak vowels. 5th international conference on speech prosody, Chicago 100185. 1-4. 
Blevins, Juliette. 1995. The syllable in phonological theory. In John Goldsmith (ed.), Handbook of phonological theory, 206-244. Cambridge, MA: Blackwell.

Browman, Catherine \& Louis Goldstein. 1988. Some notes on syllable structure in Articulatory Phonology. Phonetica 45(2-4). 140-155.

Browman, Catherine \& Louis Goldstein. 1995. Gestural syllable position effects in American English. In Fredericka. Bell-Berti \& Lawrence J. Raphael (eds.), Producing speech: Contemporary issues, 19-33. Woodbury, NY: American Institute of Physics Press.

Browman, Catherine \& Louis Goldstein. 2000. Competing constraints on intergestural coordination and self-organization of phonological structures. Bulletin de la Communication Parlée 5. 2534.

Butcher, Andrew. 2006. Australian aboriginal languages: Consonant-salient phonologies and the 'place of ariculation' imperative. In Jonathan Harrington \& Marija Tabain (eds.), Speech production: Models, phonetic processes and techniques, 187-210. New York: Psychology Press.

Byrd, Dani. 1995. C-centers revisited. Phonetica 52. 285-306.

Byrd, Dani. 1996. Influences on articulatory timing in consonant sequences. Journal of Phonetics 24. 209-244.

Byrd, Dani, Stephen Tobin, Erik Bresch \& Shrikanth Narayanan. 2009. Timing effects of syllable structure and stress on nasals: A real-time MRI examination. Journal of Phonetics 37. 97-110.

Catford, J. C. 1977. Fundamental problems in phonetics. Edinburgh: Edinburgh University Press.

Clements, George N. 1990. The role of the sonority cycle in core syllabification. In John Kingston \& Mary Beckman (eds.), Papers in laboratory phonology I, 283-333. Cambridge: Cambridge University Press.

Coleman, John. 2001. The phonetics and phonology of Tashlhiyt Berber and syllabic consonants. Transactions of the Philological Society 99. 29-64.

Dell, Francois \& Mohamed Elmedlaoui. 1988. Syllabic consonants in Berber: Some new evidence. Journal of African Languages and Linguistics 10. 1-17.

Dell, Francois \& Mohamed Elmedlaoui. 2002. Syllables in Tashlhiyt Berber and in Moroccan Arabic. Dordrecht: Kluwer.

Fougeron, Cécile \& Rachid Ridouane. 2008. On the phonetic implemenation of syllabic consonants and vowel-less syllables in Tashlhiyt. Estudios de Fonética Experimental 18. 139-175.

Gafos, Adamantios. 2002. A grammar of gestural coordination. Natural Language \& Linguistic Theory 20. 269-337.

Gick, Bryan, Fiona Campbell, Sunyoung Oh \& Linda Tamburri-Watt. 2006. Towards universals in the gestural organization of syllables: A cross-linguistic study of liquids. Journal of Phonetics 34. 4972.

Giles, Stephen B. \& Kenneth L. Moll. 1975. Cinefluorographic study of selected allophones of English /1/. Phonetica 31. 206-227.

Goldstein, Louis, Dani Byrd \& Elliot Saltzman. 2006. The role of vocal tract gestural action units in understanding the evolution of phonology. In Michael Arbib (ed.), From action to language: The mirror neuron system, 215-249. Cambridge: Cambridge University Press.

Goldstein, Louis, Ioana Chitoran \& Elisabeth Selkirk. 2007. Syllable structure as coupled oscillator modes: Evidence from Georgian vs. Tashlhiyt Berber. In Jürgen Trouvain and William J. Barry (eds.) 16th International Congress of Phonetic Sciences, Saarbrücken. 241-244.

Hermes, Anne, Martine Grice, Doris Mücke \& Henrik Niemann. 2008. Articulatory indicators of syllable affiliation in word initial consonant clusters in Italian. 8th International Seminar of Speech Production, Strasbourg. 433-436.

Honorof, Douglas \& Catherine Browman. 1995. The center or the edge: How are consonant clusters organized with respect to the vowel? 12th International Congress of the Phonetic Sciences, Stockholm 3. 552-555.

Hoole, Philip, \& Andreas Zierdt. 2010. Five-dimensional articulography. In Ben Maasen \& Pascal H. H. M. van Lieshout (eds.), Speech motor control, 331-349. Oxford: Oxford University Press. 
Hyman, Larry. 2008. Universals in phonology. Linguistic Review 25(1/2). 83-137.

Kavitskaya, Darya, Khalil Iskarous, Aude Noiray \& Michael Proctor. 2009. Trills and palatalization: Consequences for sound change. In Maria Babyonyshev, Daria Kavitskaya and Jodi Reich (eds.), Formal approaches to Slavic linguistics 17, 97-110. Ann Arbor: Michigan Slavic Publications.

Kelso, J. A. Scott. 1995. Dynamic patterns: The self-organization of brain and behavior. Cambridge, MA: Massachusetts Institute of Technology Press.

Kenstowicz, Michael \& Jerzy Rubach. 1987. The phonology of syllabic nuclei in Slovak. Language 63(3). 463-497.

Kochetov, Alexei, Marianne Pouplier \& Minjung Son. 2007. Cross-language differences in overlap and assimilation patterns in Korean and Russian. In Jürgen Trouvain and William J. Barry (eds.) 16th International Congress of Phonetic Sciences, Saarbrücken. 1361-1364.

Kozhevnikov, Valery A. \& Ludmilla A. Chistovich. 1965. Speech, Articulation and Perception. Washington, D.C.: Joint Publication Research Service 30, 543.

Krakow, Rena A. 1993. Nonsegmental influences on velum movement patterns: Syllables, sentences, stress and speaking rate. In Marie K. Huffman \& Rena A. Krakow (eds.), Nasals, nasalization, and the velum, 87-116. San Diego: Academic Press.

Krakow, Rena A. 1999. Physiological organization of syllables: A review. Journal of Phonetics 27. 23-54.

Král', Ábel, \& Ján Sabol. 1989. Fonetika a fonológia [Phonetics and Phonology]. Bratislava: Slovenské pedagogické nakladatel'stvo.

Lisker, Leigh. 1995. English /w, j/: Frictionless approximants or vowels out of place? In Fredericka Bell-Berti \& Lawrence J. Raphael (eds.), Producing speech: Contemporary issues. For Katherine Safford Harris, 129-142. Woodbury, NY: American Institute of Physics Press.

Löfqvist, Anders \& Vincent L. Gracco. 1999. Interarticulator programming in VCV sequences: Lip and tongue movements. Journal of the Acoustical Society of America 105(3). 1864-1876.

MacNeilage, Peter F. \& Barbara L. Davis. 2000. On the origin of internal structure of word foms. Science 288. 527-531.

Marin, Stefania \& Marianne Pouplier. 2010. Temporal organization of complex onsets and codas in American English: Testing the predictions of a gestural coupling model. Motor Control 14(3). 380407.

McCarthy, John J. 2003. OT constraints are categorical. Phonology 20(1). 75-138.

Nam, Hosung. 2007a. Gestural coupling model of syllable structure. New Haven, CT: Yale University dissertation.

Nam, Hosung. 2007b. Syllable-level intergestural timing model: Split-gesture dynamics focusing on positional asymmetry and moraic structure. In Jennifer Cole \& José Ignacio Hualde (eds.), Papers in laboratory phonology 9, 483-506. Berlin: Mouton de Gruyter.

Nam, Hosung, Louis Goldstein \& Elliot Saltzman. 2009. Self-organization of syllable structure: A coupled oscillator model. In François Pellegrino, Egidio Marisco, Ioana Chitoran \& Christophe Coupé (eds.), Approaches to phonological complexity, 299-328. Berlin: Mouton de Gruyter.

Nittrouer, Susan, Kevin G. Munhall, J. A. Scott Kelso \& Betty Tuller. 1988. Patterns of interarticulator phasing and their relation to linguistic structure. Journal of the Acoustical Society of America 84. $1653-1661$.

Ohala, John \& Haruko Kawasaki-Fukumori. 1997. Alternatives to the sonority hierarchy for explaining segmental sequential constraints. In Stig Eliasson \& Ernst Håkon Jahr (eds.), Language and its ecology: Essays in memory of Einar Haugen, 343-365. Berlin: Mouton de Gruyter.

Öhman, Sven E. 1966. Coarticulation in VCV utterances: Spectrographic measurements. Journal of the Acoustical Society of America 39(1). 151-168.

Perkell, Joseph. 1969. Physiology of speech production. Cambridge, MA: Massachusetts Institute of Technology Press.

Pike, Kenneth L. 1943. Phonetics: A critical analysis of phonetic theory and a technic for the practical description of sounds. Ann Arbor: University of Michigan Press. 
Pouplier, Marianne. accepted. The gestural approach to syllable structure: Universal, language- and cluster-specific aspects. In Susanne Fuchs, Melanie Weirich, Daniel Pape \& Pascal Perrier (eds.), Speech planning and dynamics. Berlin: Peter Lang.

Prince, Alan, \& Paul Smolensky. 2004. Optimality Theory: Constraint interaction in generative grammar. Malden, MA and Oxford: Blackwell.

Proctor, Michael. 2009. Gestural characterization of a phonological class: The liquids. New Haven, CT: Yale University dissertation.

Redford, Melissa. 1999. An articulatory basis for the syllable. Austin, TX: University of Texas dissertation.

Ridouane, Rachid. 2003. Suite de Consonnes en Berbère Chleuh: Phonétique et Phonologie. Paris: Université de Paris III PhD thesis.

Ridouane, Rachid and Cécile Fougeron. 2011. On the nature and distribution of schwa-like elements in Tashlhiyt clusters. In this volume.

Rubach, Jerzy. 1993. The lexical phonology of Slovak. Oxford: Clarendon Press.

Selkirk, Elisabeth. 1982. The syllable. In Harry van der Hulst \& Norval Smith (eds.), The structure of phonological representations, vol. 2, 337-381. Dordrecht: Foris.

Shaw, Jason A., Adamantios Gafos, Philip Hoole \& Chakir Zeroual. 2009. Temporal evidence for syllabic structure in Moroccan Arabic: Data and model. Phonology 26. 187-215.

Shaw, Jason A., Adamantios Gafos, Philip Hoole \& Chakir Zeroual. in press. Dynamic invariance in the phonetic expression of syllable structure: A case study of Moroccan Arabic consonant clusters. Phonology.

Sommer, Bruce. 1970. An Australian language without CV syllables. International Journal of American Linguistics 36(1). 57-58.

Sproat, Richard \& Osamu Fujimura. 1993. Allophonic variation in English /1/ and its implications for phonetic implementation. Journal of Phonetics 21(3). 291-311.

Stetson, Raymond H. 1951. Motor phonetics: A study of speech movements in action. Amsterdam: North-Holland.

Tillmann, Hans Günther. 1964. Das phonetische Silbenproblem. Eine theoretische Untersuchung. Bonn: Rheinische Friedrich-Wilhelms-Universität dissertation.

Vennemann, Theo. 1991. Syllable structure and syllable cut prosodies in Modern Standard German. In Pier Marco Bertinetto (ed.), Certamen Phonologicum II. Papers from the 1990 Cortona phonology meeting, 211-243. Torino: Rosenberg \& Sellier.

Vennemann, Theo. 1992. Universelle Nuklearphonologie mit epiphänomenaler Silbenstruktur. Jahrestagung der Deutschen Gesellschaft für Sprachwissenschaft, Bremen, 25.-28.2.1992.

Zsiga, Elizabeth. 2000. Phonetic alignment constraints: Consonant overlap and palatalization in English and Russian. Journal of Phonetics 28. 69-102.

Zsiga, Elizabeth. 2003. Articulatory timing in a second language: Evidence from Russian and English. Studies in Second Language Acquisition 25(3). 399-432. 